\title{
ROMANCE ENCLITIC ORDERING AND UNIVERSAL GRAMMAR
}

\author{
JOHAN ROORYCK
}

\section{INTRODUCTION*}

In all ${ }^{1}$ Romance languages, clitics have to follow an nonnegated imperative. This is illustrated for French, Italian and Spanish and European Portuguese in (1):

$$
\begin{aligned}
& \text { a. Fais-le! (Fr.)/ Falo! (It.)/ Hazlo! (Sp.)/ Fá-lo! (Port.) } \\
& \text { do-2sG it(CL) } \\
& \text { b. *Le fais!/ *Lo fa!/ *Lo haz!/ *O faz! } \\
& \text { it(CL) do-2sG }
\end{aligned}
$$

The observation also holds for Catalan, Romanian, Sardinian (Jones 1988: 337), Rhaeto-Romance (Haiman 1988: 377), and Corsican (Albertini 1972: 45) in (2):2

* I would like to thank Denis Bouchard, Marcel den Dikken, Marco Haverkort, Brian Joseph, Richard Kayne, Carlos Otero, Raffaella Zanuttini and a reader for The Linguistic Review for comments and discussion. The usual disclaimers apply. Thanks to Pierre Pica for long distance inspiration, and to Judy Bernstein for extensive discussions. Thanks also to Leslie Gabriele for the data of Brazilian Portuguese and to Aleksander Murzaku for Albanian. Previous versions of this article were presented at the 1992 LSA Meeting in Philadelphia, January 11, 1992, at the 22nd Annual Linguistic Symposium on Romance Languages, El Paso, February 20-23, 1992, at the XVIII Incontro di grammatica generativa. Ferrara, February $27-29,1992$, and at the séminaire de syntaxe avancée of the Universite Paris 8, Saint-Denis, June 15, 1992.

1 See $\$ 5$ for some apparent counterexamples involving imperatives with subjunctive form.

2 The observation also extends to those Romance dialects which are diachronically of the "langue d'ơn' type. Rézean (1976:69) gives examples from Vendéen: dun mo ld (give2sG. to-meCL itCL), and Remacle (1952:250) for Walloon: prinds-è (take-2sG of-it(CL)). For Occitan, Sauzet (1986:153) observes that imperatives display enclitic ordering: Dona-li de pan (give-2SG him(CL) some bread). This observation is confirmed for the different Occitan dialects by data attested in the versions of the Parabole de l'enfant prodigue cited in Bec (1967), e.g. Auvergnat:

$$
\begin{aligned}
& \text { Partatjatz vòstre ben e bailatz-me ço que deve aver. } \\
& \text { divide-2:HON your goods and give-2:HON. me(CL) that what should-1SG have.' }
\end{aligned}
$$


(2) a. Fes-ho! (Cat.)/ Pune-o! (Rom.)/ Píkalu (Sard.)/ Do m! (Rh. Rom) do-2SG it(CL)/ set-2SG it(CL)/ take-2SG it(CL)/ give-2SG me(CL)

b. Dálluli/ Dállilu (Cors.) give-2SG it(CL) to-him(CL)/ give-2SG to-him(CL) it(CL)

The enclitic ordering in positive imperatives is not restricted to Romance, but also extends to other, only distantly related, languages: Albanian (3a,b) (Newmark et al. 1982, quoted by Rivero 1988), Modern Greek (3c), and Modern Macedonian (Joseph 1983):
a. Digj-
e!
Rivero (1988, fn. 10(ia)) burn-IMP:2sG it(CL)
b. Mos e digi!
Rivero (1988, fn. 10(ib)) NEG it(CL) burn-IMP:2SG
c. Grapse to! write-IMP:2SG it(CL)
Rivero (1988, ex.(45))

Surprisingly, the observation holds even for languages which never allow clitics to follow the verb otherwise. In French for instance, the only case where clitics follow the verb is in the positive imperative. It is well known for instance that in Spanish and Italian (4a,b) the clitics follow the infinitive (see Kayne 1991a for an analysis of this phenomenon), but in French this option is excluded, (4c):
a. Quiero hacerlo. want-1SG do it(CL)
b. Voglio farlo. want-1SG do it(CL)
c. Je veux le faire/*faire le.
I want $\{\mathrm{it}(\mathrm{CL}) \mathrm{do} / \mathrm{do} \quad \mathrm{it}(\mathrm{CL})\}$

This striking generalization is a major puzzle for contrastive linguistics: why do so many languages exhibit this particular ordering of clitics with imperatives? It could of course be claimed that there is a rule postposing clitics in positive imperatives, but such a solution would fall short of explaining why this specific ordering is required across languages in the first place. If the postverbal ordering were rule-governed or subject to some low level grammatical constraint, one would expect much more variation crosslinguistically than what is actually the

For Gascon, these data are confirmed by Rohlfs (1977:185): $d a m^{\prime} O c$ (give-2sG to-me(CL) it(CL)). Interestingly, as illustrated in (2b), the respective ordering of accusative and dative clitics in Corsican is free (Albertini 1972:44-45). 
case. The issue is an interesting one when viewed from the perspective of a modular grammar in which modules and principles interact to generate acceptable sentences. In such a framework, the postverbal ordering of clitics with positive imperatives is likely to involve a very general principle of the grammar. It is likely that the same principle which is responsible for enclitic ordering in imperatives is also responsible for enclitic ordering in Spanish and Italian infinitives. We would like to show that the position of clitics in both imperatives and infinitives follows from such a very general principle operating in the syntax which involves the core relation of government, Relativized Minimality (Rizzi 1990). Relativized Minimality can be defined as follows (Rizzi 1990):

$\mathrm{X} \alpha$-governs $\mathrm{Y}$ only if there is no $\mathrm{Z}$ such that

(i) $\mathrm{Z}$ is in a base-generated position;

(ii) $Z$ is a typical potential $\alpha$-governor for $Y$;

(iii) $\mathrm{Z}$ c-commands $\mathrm{Y}$ and does not $\mathrm{c}$-command $\mathrm{X}$; where $\alpha$-government ranges over $\mathrm{A}, \mathrm{A}^{\prime}$, and $\mathrm{X}^{0}$ government.

This means that in a linear syntactic string $\mathrm{X}-\mathrm{Z}-\mathrm{Y}, \mathrm{X}$ cannot govern $\mathrm{Y}$ if an element $Z$ intervenes which is in the same type of phrase structure position (argument, non-argument or head position) as $\mathrm{X}$ and $\mathrm{Y}$. Let us take an example from Rizzi (1990: 11, ex. (24)) to make this clear:
a. They could have left.
b. Could they $t$ have left.
c. *Have they could $t$ left.

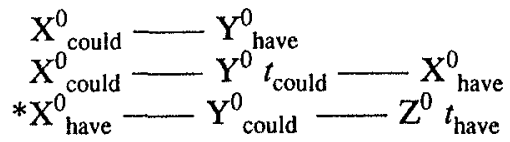

In $(6 \mathrm{c})$, have has moved to a position $\left(\mathrm{C}^{0}\right)$ from which it cannot govern its trace, since another head, the modal could, intervenes between have and its trace. Since the trace of have is not governed, the sentence is ruled out by the Empty Category Principle which states that every trace should be governed. We would like to show that the grammatical mechanism which excludes $(6 \mathrm{c})$ also excludes (1b). It is our purpose to show how a modular theory of syntax can explain the at first sight puzzling generalization involving clitic ordering in imperatives. In order to achieve this goal, we will assume the groundbreaking work of the last few years on the multi-layered nature of functional categories (Pollock 1989; Belletti 1990), and the incorporation of clitics (Kayne 1989). The analysis is interesting because it shows how a modular analysis can capture syntactic generalizations such as the one expressed in (1-3) on the basis of independently motivated principles and properties. 


\section{FRAMING THI PROBLEM}

In this section, we will first take a closer look at the variation of clitic ordering in Romance. We will furthermore try to establish how the problem of enclitic ordering has to be framed. At first sight, two options are open: either the verb moves over the base-generated clitics, or the clitics are left behind by the verb on its way up to the relevant functional categories. We will show that the problem at hand really involves the question why clitics are left behind by the verb, and that in principle, nothing seems to prevent the verb from moving up with its clitics. Finally, we will formulate the conjecture that the nature of the $\mathrm{Agr}^{0}$ morphemes in imperatives and infinitives forces clitics to be left behind.

Contrary to the generalized enclitic ordering in positive imperatives, Romance exhibits a great deal of variation with respect to clitic ordering in negated imperatives. Kayne (1991b) observes that in Northern Italian, the enclitic ordering in negative imperatives ( $7 b$ ) is by far preferred to the proclitic ordering which is common in the dialects of the Center. This distribution is paralleled in the infinitival negative imperatives (8) of these dialects:
a. Non lo fate! NEG it(CL) do-INF
b. Non fatelo! NEG do-2PL it(CL)
a. Non farlo! NEG do-INF it(CL)
b. Non lo fare! NEG it(CL) do-INF

(=Kayne 1991b, ex. (47))

The possibility for clitics to precede or follow the negated imperative is also reported for Rhaeto-Romance (Haiman 1988: 377). Spanish, Catalan, and Portuguese negated imperatives which use the subjunctive morphology do not allow for the enclitic option. The following are from Spanish:
a. Hazlo!/
Hágalo!/
do-2SG:IMP it(CL)/ do-2SG:HON:SUBJ it(CL) (honorific you)/
Hagámoslo!
do-1 PL it(CL) (exhortative)
b. No lo hagas! / *No lo haz!
NEG it(CL) do-2sG:SUBJ (not honorific)
c. *No hágaslo/ *No hágalo
NEG do-2SG:SUBJ it(CL)/ NEG do-3SG:SUBJ it(CL) (honorific you) 
In Spanish infinitival imperatives, clitics cannot precede the verb in any dialect that we are aware of:
a. No hacerlo!
NEG to do it(CL)
b. *No lo hacer!
NEG it(CL) to do

Outside of the imperative system in Romance, clitics do not necessarily precede the verb either. We have already pointed out the fact that clitics follow infinitives in Spanish and Italian. Besides the variation in clitic ordering in negated imperatives in Romance, the position of the clitics exhibit a great deal of variation even in tensed clauses across Romance languages, despite the fact that the core position is proclitic. In Portuguese, clitics precede or follow the verb in tensed clauses according to a very complex rule system. In European Portuguese, clitics have to follow the verb in root clauses whereas they mostly precede the verb in embedded clauses. However, in root clauses, the presence of quantifiers on the subject or negation forces proclitic ordering. With infinitives, the choice of the embedding preposition seems to be relevant (12) (see Pizzini 1981 for an analysis of these data).
a. Disseram-me
que ele te
escreveu. tell-PAST:3PL me(CL) that he to-you(CL) write-PAST:3SG
b. Contaste-lhe a historia? tell-PAST:2SG him(CL) the story
c. Vi-o. see-PAST:1SG $\{\mathrm{ithim(CL)}\}$
d. Não o vi./ Ninguem o viu.
e. Todos me disseram que ele te escreveu. all me(CL) tell-PAST:3PL that he to-you(CL) write-PAST:3SG NEG $\{\mathrm{it} / \mathrm{him}(\mathrm{CL})\}$ see-PAST:1SG/ nobody it/him(CL) $\}$ see-PAST:3SG
a. Começou
a vê-lo. begin-PAST:3SG to see it/him(CL)
b. Vieram para la escrever. come-PAST:3PL to it(CL) write

Brazilian Portuguese has different rules for clitic-verb ordering, which mostly indicate a shift towards the proclitic position. These examples may suffice to indicate the variation of clitic ordering in those cases which do not involve positive imperatives.

We do not want to go into the specifics of clitic ordering outside of the 
imperative and infinitival system in Romance here. The variation in clitic ordering attested in Portuguese must be due to language specific factors which we will not investigate here (see Rouveret 1989). However, it is not likely that language specific factors are responsible for enclitic ordering in imperatives, since this ordering seems exceptionless even across language families (cf. supra (3a)). In view of the attested variation of clitic ordering in nonimperative contexts, the absence of variation in clitic ordering with positive imperatives is all the more surprising. It seems worthwhile to investigate whether this enclitic ordering in imperatives can be made to follow from general principles of the grammar.

Let us first try to show how the problem of enclitic ordering in positive imperatives can be formulated in the framework assumed here. Following Baker (1988) and Kayne $(1989,1991 a)$, it will be assumed that the core position of clitics in Romance is obtained by adjunction (incorporation) of the $\mathrm{X}^{0}$ clitics to the left of the verb. The verb then subsequently moves to its functional projections where it adjoins first to the left of $T^{0}$ and subsequently to $\mathrm{AgIS}^{0}$ (Belletti 1990). Adjunction to the left of the functional projections ensures that the verbs picks up tense features in $\mathrm{T}^{0}$ before receiving agreement features in (14), following Belletti (1990) in assuming that $\mathrm{AgrS}^{0}$ selects TP. Furthermore, we will accept with Rivero (1988) that positive imperatives as in (1-2) involve head movement of the V-T-Agr complex to $C^{0}$. This movement to $C^{0}$ can be motivated. First of all, imperatives express a modality (close to the classical grammarian's definition of irrealis/potentialis) that can be associated with the temporal/ modal $C^{0}$ morpheme. Rivero (1988) claims that the imperative $C^{0}$ makes the verb function as a performative operator. Moreover, several languages have specific morphemes for imperatives which differ from indicative or subjunctive morphology and which must be associated with a distinct functional category. Rivero (1988) labels this type of imperatives 'true' imperatives for the languages of the Balkans, as opposed to 'surrogate' imperatives which correspond morphologically existing tenses in the system (cf. (3)). This imperative morphology then forces movement of the verbal complex to $\mathrm{C}^{0}$ in the case of positive imperatives.

With respect to negative imperatives, Rivero (1988) claims that negation prevents the verb from moving beyond $\mathrm{AgrS}^{0}$ and $\mathrm{T}^{0}$ to its specific imperative Agr morphology in $\mathrm{C}^{0}$ which lies beyond NegP. This is an important argument in favor of movement to $\mathrm{C}^{0}$ in imperatives, since it allows for an explanation of the contrast in (9ab). In (9a), the verb moves all the way to its specific Agr morphology in $\mathrm{C}^{0}$. In (9b), however, it does not move any farther than $\mathrm{AgrS}^{0}$, since negation blocks movement of the verb to $\mathrm{C}^{0}{ }^{3}$

3 Zanuttini (1991: 75-79) argues against Rivero's (1988) analysis of negation blocking movement to $C^{0}$. Zanutini (1991) argues that if negation were to block movement to $C^{0}$, negative gerundival 

a. Hazlo !
do it(CL)
[CP $\mathrm{Ha}-\mathrm{z} \mathrm{AgrC}^{0}$ [IP $_{\mathrm{IP}}$ lo [VP]]]
b. No lo hagas!
NEG it(CL) do
[ ${ }_{\mathrm{CP}} \mathrm{AgrC}^{0}$ [IP $_{\mathrm{P}}$ no lo hagas [VP]]]

It can be assumed that the imperative morphology in $C^{0}$ which cannot be expressed in negative imperatives functions in many Romance dialects as an operator triggering the subjunctive morphology in the lower $\operatorname{AgrS}^{0}$ and $\mathrm{T}^{0}$ $(9 b-13 b)$. The subjunctive morphology then appears in the same way as in embedded clauses which are governed by a verb ruling the subjunctive: in these cases, the value of $\mathrm{C}^{0}$ which is lexically determined by the governing $\mathrm{V}$ also triggers the subjunctive in the embedded $\mathrm{T}^{0}$. Rivero's (1988) claim that the morphology of 'true' imperatives is located in $\mathrm{C}^{0}$ and forces movement of the verbal complex hence seems to be well motivated.

In itself, head movement of the verbal complex to $C^{0}$ cannot explain why clitics have to stay behind in $\mathrm{AgrS}^{0}$. In principle, the complement clitics should move with the $\mathrm{V}^{0}-\mathrm{T}^{0}-\mathrm{AgrS}^{0}$ complex to $\mathrm{C}^{0}$. After all, in declarative sentences the cl- $\mathrm{V}^{0}$ complex successively moves to $\mathrm{T}^{0}$ and $\mathrm{AgrS} \mathrm{S}^{0}$, yielding (14a) with the structure in $(14 b):^{4}$

adverbial clauses such as (i) in Italian should be out, since they involve $V^{0}$ to $C^{0}$ movement under Rizzi's (1982) classical analysis.

Non avendo Mario accettato di aiutarci, non potremo risolvere il problema.

'Mario not having accepted to help us, we won't be able to solve the problem.'

However, it might be that the movement-blocking capacity of negation does not apply to the auxiliaries essere 'be' and avere 'have' which more closely resemble functional categories. It could be that negation only blocks 'strong' verbs which are fully lexical categories. Restricting our attention to imperatives, it is certainly true that the order negation + imperative + clitic exists in Romance, as in (7b). Kayne notes that this order is attested only in those Romance dialects that have the order infinitive + clitic. If blocking of $\mathrm{V}$ to $\mathrm{C}$ by negation were simply contrained language specifically, there would be no explanation for this correlation. In the analysis adopted below, the correlation Inf $+\mathrm{Cl}$ and $\mathrm{Imp}+\mathrm{Cl}$ can be accounted for (See $\$ 3$ for the analysis of this case).

4 In this structure, we assume that movement of complex head clusters leaves behind internally structured traces. This representation simply takes seriously the idea that movement must be completely 'transparent'. The representation of the amalgamated verb under $\mathrm{AgrS}^{0}$ is simplified for purposes of illustration. As it stands, the representation is not very intuitive since it suggests that the clitics are more closely connected to the verbal stem than the verbal affix. Taking into account Roberts' (1991) discussion of the difference in incorporation of clitics and verbal affixes, the proper representation under $\mathrm{AgrS}^{0}$ in (14b) would have to reflect this different relation. For Roberts (1991), cliticization involves adjunction at the $\mathrm{X}^{0}$ level, while affixation takes place at a sublexical level $\mathrm{X}^{-1}$. This difference of incorporation captures the difference of connectivity between clitics and affixes. Roberts' (1991) analysis does not have major consequences for the analysis which will be developed here in terms of Relativized Minimality. For Roberts (1991), $\mathrm{X}^{-1}$ affixes do count as intervening 
a. Tu le regardais

you it/him(CL) watched

b.

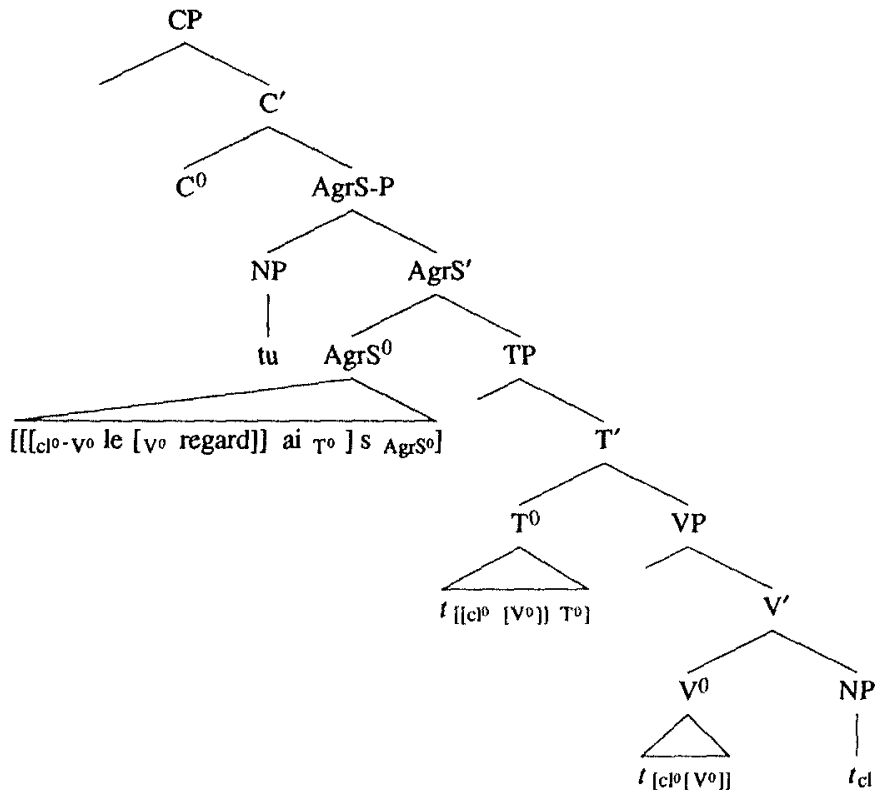

Within the general framework sketched so far, the question with clitic ordering in positive Romance imperatives is to understand why the verb alone moves to $\mathrm{C}^{0}$, since this obviously is the exceptional case.

At this point, it might be objected that the problem should not be framed in this way. Adapting Jaeggli (1986), it may be claimed contra Kayne (1989) that clitics are not base-generated in object position, but that they are base-generated in $\mathrm{AgrS}^{0}$. It would then suffice to say that clitics never move with the verb, and that the Romance verb simply moves beyond the clitics to $\mathrm{C}^{0}$ in imperatives. For the problem to arise in the way we claim it does, it must first be shown that this simpler hypothesis is not tenable. We would like to show that this simpler analysis raises several problems. First of all, there is a problem with respect to adjunction, since the verb would have to move from its base position to $\mathrm{AgrS}^{0}$ and nestle itself in between the clitic and the verbal agreement. It is not clear

governors for the trace of incorporated $V^{0}$. Pursuing the logic of Roberts (1991) analysis, $X^{-1}$ affixes must also be intervening governors for the traces of incorporated $X^{0}$ clitics which are sisters to $V^{0}$. For our analysis of the postverbal ordering of clitics in imperatives, this means that the Agr $\mathrm{C}^{0}$ imperative morphology can act as an intervening governor for the relation between the clitic incorporated under $\mathrm{AgrC}^{\circ}$ and the trace of the clitic in $\mathrm{AgrS}^{\circ}$. The simplification in (14) and in the other representations in this paper is justified since it has no direct consequences for the analysis to be developed (but see $\$ 4$, in fine). 
how this can be done without ad hoc stipulations on adjunction. A second and more important problem for this approach concerns a factual matter. Let us briefly go into the problem of the position of verbs and adverbs in Romance. The ordering of adverbs with respect to tensed verbs and infinitives has allowed Pollock (1989) to argue that tensed verbs in French move up to $\mathrm{AgrS}^{0}$ beyond the adverb souvent 'often' in (15a). Infinitives stay put in their base position, or in a position below the adverb (15b).
a. Marie (*souvent) parle (souvent) de lui.
'Mary (often) talks (often) about him.'
b. Marie prétend [(souvent) parler (*souvent) de lui]
'Mary claims to (often) talk (often) about him.'

Belletti (1990) argues that Italian differs from French in that infinitives moves up to $\mathrm{AgrS}^{0}$ in the same way as tensed verbs. The main argument for this is the position of adverbs, which is the same in both cases:
a. Maria (*spesso) parlava (spesso) di lui.
'Mary (often) talks (often) about him.'
b. Maria sostiene di (*spesso) parlare (spesso) di lui.
'Mary claims to (often) talk (often) about him.'

Let us now see how this analysis of Italian infinitives raises a problem for the base-generation of clitics in $\mathrm{AgrS}^{0}$. In Romance languages such as Italian and Spanish, clitics are postposed to infinitives as illustrated in (10). If both infinitives and tensed verbs move to the same structural position in Italian, we would be hard put to explain why clitics are postverbal in the case of infinitives and preverbal in the case of tensed verbs. This problem would remain even if clitics were base-generated as adjuncts to $\mathrm{AgrS}^{0}$.

We may conclude that the problem of postverbal ordering of clitics in Romance positive imperatives does arise in the way we claim it does. The question why the verb complex does not take its clitics with it while moving to $\mathrm{C}^{0}$ is a relevant one. We will moreover show that our analysis of the postverbal position of clitics in positive imperatives in Romance can be extended to explain the position of clitics in Spanish and Italian infinitives, given the movement of infinitives to $\mathrm{AgrS} \mathrm{S}^{0}$ in these languages.

If it is accepted with Kayne (1989) that clitics incorporate into the verb and then move further up with the verb through the functional projections, the question remains why they do not move up with the verb all the way to $C^{0}$. We would like to say that this is due to the nature of $\mathrm{C}^{0}$ in imperatives. Imperatives not only have specific modal (irrealis/potentialis) properties that are determined by $\mathrm{C}^{0}$, they also have specific agreement properties which are restricted to 
second person singular and plural (honorific or not), or to first person plural for the exhortative (cf. (9a)). Extending to root clauses Rizzi's (1990) suggestion that embedded $\mathrm{C}^{0} \mathrm{~s}$ in English can contain either the complementizer that or a nonovert $\mathrm{AgrC}^{0}$, these restricted $\mathrm{Agr}$ features can be attributed to an imperative Agr morpheme in $C^{0}$. In example (13), we have labeled this imperative $C^{0}$ with agreement features $\mathrm{AgrC}^{0}$. The fact that $\mathrm{Agr}^{0}$ features are present in $\mathrm{C}^{0}$ is particularly plausible in view of the observations by Rivero (1988) and Zanuttini (1991) that languages which display specific imperative morphology do not allow this morphology to show up in negative imperatives. Recall that where negation is present the verbs is prevented from moving to $\mathrm{C}^{0}$ and attaching to the imperative morphology.

Interestingly, the hypothesis that an $\mathrm{Agr}^{0}$ morpheme is in some way responsible for enclitic ordering can be extended to the postverbal ordering of clitics in Spanish and Italian infinitives. As pointed out in the preceding section, there is evidence from the position of temporal adjuncts that the verb moves up to $\mathrm{AgrS}^{0}$ in Spanish and Italian, but not in French. This description has been further refined by Kayne (1991). Kayne (1991a) claims that in French, $V^{0}$ moves up with its clitics to an INF projection containing the infinitival morphology which is added to the verbal stem. This projection is preceded by adverbs of the souvent 'often' type, exemplified in (17b). Sardinian moves the clitic + infinitival $\mathrm{V}^{0}$ complex up to $\mathrm{T}^{0}$ and has an order clitic + infinitive + adverb as in (17b) (Kayne 1991a). In Italian and Spanish, following Belletti (1988), the infinitival $\mathrm{V}^{0}$ moves up to $\mathrm{AgrS}^{0}$, leaving behind its clitics in $\mathrm{T}^{\circ}$ (cf. (4a) and $(17 \mathrm{c}))$.

$$
\begin{aligned}
& \text { a. } \left.\ldots \mathrm{AgrS}^{0} \ldots \mathrm{T}^{0} \ldots \mathrm{Adv} \ldots\left[\left[\mathrm{Cl}^{0}\left[\mathrm{~V}^{0}\right]\right] \mathrm{Inf}^{0}\right] \ldots t_{\left[\mathrm{Cl}^{\circ}\right.}\left[\mathrm{V}^{\circ}\right]\right] \\
& \text { b. } \ldots \mathrm{AgrS}^{0} \ldots\left[\left[\left[\mathrm{Cl}^{0}\left[\mathrm{~V}^{0}\right]\right] \operatorname{Inf}^{0}\right] \mathrm{T}^{0}\right] \ldots \mathrm{Adv} \ldots
\end{aligned}
$$

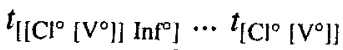

$$
\begin{aligned}
& \text { c. } \left.\quad \ldots\left[\left[\left[t_{\mathrm{C}^{\circ}}\left[\mathrm{V}^{0}\right]\right] \operatorname{Inf}^{0}\right] \mathrm{T}^{0}\right] \mathrm{AgrS}^{0}\right] \ldots t_{\left[\mid\left[\mathrm{Cl}^{\circ}\left[\mathrm{V}^{\circ}\right] \mid \operatorname{Inf}\right] \mathrm{T}^{\circ}\right]} \ldots \text { Adv ... }
\end{aligned}
$$

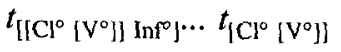

Again, it seems that the infinitival $\mathrm{AgrS}^{0}$ somehow forces clitics to be left behind in Italian and Spanish. In French, the verb does not move up to $\mathrm{AgrS}^{0}$. Consequently, clitics remain in their left-adjoined position to the verb. We may then formulate the following approximative generalization:

(18) Whenever a verb is related through movement with the $\mathrm{Agr}^{0}$ morphemes associated with imperative or infinitival morphology, it must leave clitics behind. 
This formulation captures both the case of Italian-Spanish, where clitics follow the verb since the verb has moved up to $\mathrm{AgrS}^{0}$, and the case of FrenchSardinian where the verb has not moved high enough for it to leave its clitics behind. Why is this the case? What properties of this morphology enable it to force clitics to be left behind when the verb moves up? Let us therefore analyze in some detail the feature composition of the functional categories involved in imperatives and infinitives.

\section{The ANAPHORIC NATURE OF INFINITIVAL AgRS ${ }^{0}$ AND IMPERATIVE AGRC ${ }^{0}$}

Infinitives and imperatives are similar in many respects: both imperatives and infinitives do not license overt subjects. For Beukema and Coopmans (1989), this is due to the [-tensed] value of the temporal morphemes in imperatives and infinitives which do not allow nominative Case to be assigned to the subject position. This claim has to be modified to the extent that the temporal value of imperatives certainly is not characterized by the absence of tense. Contrary to the suggestion by Beukema and Coopmans (1989), it cannot be the case that imperatives have a [-tensed] feature which would be more or less identical to that of infinitives: Latin has a temporal morpheme for the future imperative:

$$
\begin{array}{ll}
\text { a. } & \text { ama } \\
\text { love-IMP:PRES:2SG } \\
\text { c. amate } \\
\text { love-IMP:PRES:2PL }
\end{array}
$$
b. amato
love-IMP:FUT:2SG
d. amatote
love-IMP:FUT:2PL

It is more accurate to say that the tense of imperatives is restricted to non past tense. It remains true however that past imperative morphology does not seem to exist. It might therefore be useful to characterize the temporal/modal value of imperatives as [-realized], a temporal/modal value which is compatible with future, but not with past interpretation. This characterization has been proposed for the tense of infinitives by Stowell (1982). This definition of the tense of infinitives is not new. It has long been noted that the semantic interpretation of the infinitival morphology corresponds to a temporal/modal notion. Bresnan (1972) observes that infinitival complements refer to 'something hypothetical or unrealized'. Guillaume (1929) had already defined the infinitival tense as a tense 'in posse': it expresses 'potential' time, or eventuality, which is opposed to tense 'in esse', a 'real' or finite time reference linked to the time axis. Stowell (1982) makes a similar observation stating that the tense of infinitives must be semantically interpreted as unrealized or as a 'possible future'. Reinterpreting Beukema and Coopmans (1989), we then propose that imperatives and infinitives have the temporal feature [-realized] in common rather than the feature [-tensed]. 
How can this common [-realized] property of infinitives and imperatives be related to the position of clitics in these cases? In order to offer an answer to this question, we have to take a closer look at the $\mathrm{Agr}^{0}$ morphemes that are associated with [-realized] $\mathrm{T}^{0}$ morphemes. During the 1980's it has repeatedly been argued that control theory can be partially reduced to Binding Theory, since the infinitival PRO takes the sentence in which the infinitive is embedded as the domain in which its antecedent is to be found. In the following sentence, the infinitival subject (the anaphoric $\mathrm{AgrS}^{0}$ ) cannot be bound by the subject of a superordinate clause:

You said that Harry promised to shave himself/*yourself.

Borer (1989) has argued that the $\mathrm{AgrS}^{0}$ of infinitives is what is anaphoric in nature rather than the PRO subject of infinitives. Let us assume that this is indeed the case. ${ }^{5}$ To say that the infinitival $\mathrm{AgrS}^{0}$ is anaphoric in nature is tantamount to saying that it is morphologically identical to the overt clitic se/si, which is the anaphoric clitic in Romance.

$$
\begin{aligned}
& \text { Giovanni si vede. } \\
& \text { Giovanni self(CL) sees } \\
& \text { 'Giovanni sees himself.' }
\end{aligned}
$$

We may conclude that the infinitival $\mathrm{T}^{0}$ can be characterized as [-realized], and is associated with an anaphoric $\mathrm{AgrS}^{\circ}$.

It is important to point out that tensed $\mathrm{AgrS}^{0}$ should not be defined as an anaphor in terms of the Binding Theory: it is nor an anaphor, nor a pronoun, but simply subject to SpecHead agreement with whatever is the subject at S-structure. Tensed $\mathrm{T}^{0}$ can only be associated with an $\mathrm{AgrS}^{0}$ that is not defined in terms of the Binding Theory, since embedded tensed sentences are never subject to control in Romance. The absence of control in tensed sentences shows

5 Contra Borer (1989), Rooryck (1991) argues that $\mathrm{AgrS}^{0}$ does not move to $\mathrm{C}^{0}$ in order to extend its Binding domain to the matrix clause (cf. Manzini 1983). Following Kayne (1991a), Rooryck (1991) assumes that the infinitival $\mathrm{AgrS}^{0}$ (PRO for Kayne) cannot be bound in its own $\mathrm{X}^{\max }$ because there is no position which might contain a potential binder. Hence, the next category up is the Binding domain for $\mathrm{AgrS}^{0}$. Extending insights of Stowell (1982), Rooryck (1991) develops a modular analysis of control in which the matrix verb determines control via aspectual coindexation of the [-realized $] C^{0}$ with aspectual subevents in the event structure of the matrix verb. This lexical coindexation of the infinitival $\mathrm{C}^{0}$ restricts Binding of the anaphoric infinitival $\mathrm{AgrS}^{0}$ in the matrix clause. Since the infinitival $\mathrm{AgrS}^{0}$ is coindexed with the infinitival $\mathrm{C}^{0}$, anaphoric $\mathrm{AgrS}^{0}$ can only be bound by those arguments which are lexically represented in the subevent the infinitival $\mathrm{C}^{0}$ is coindexed with. In other words, partial coindexation of $\mathrm{C}^{0}$ with the governing control verb restricts the Binding antecedents for anaphoric $\mathrm{AgrS}^{0}$. This analysis of control eliminates control theory, since control arises through a modular interaction of general principles of the grammar. 
that tensed $\mathrm{AgrS}^{0}$ is fundamentally different from the $\mathrm{AgrS}^{0}$ associated with [-realized] tense. This difference is further corroborated by the difference in the actual morphemes for both types of $\mathrm{AgrS}^{0}$. Overt agreement morphemes for tensed $\mathrm{T}^{0}$ (e.g. 1 PL / $\tilde{\mathrm{o}} /, 2 \mathrm{PL} / \mathrm{e} / \mathrm{in}$ French) always appear in the context of tensed $\mathrm{T}^{0}$ morphemes (e.g. imperfective /j/ for 1PL and $2 \mathrm{PL}$ in French nous mangions 'we were eating'). These tensed agreement morphemes never co-occur with the infinitive /e/ morphology associated with untensed $\mathrm{T}^{0}$ of manger. 'eat'. Conversely, the infinitival $\mathrm{Agr}^{\circ}$, which remains morphologically unexpressed in Romance, will always cooccur with [-realized] $\mathrm{T}^{0}$. Functional agreement and tense categories with the same 'settings' always co-occur.

Let us now see how the characterization of anaphoric $\mathrm{Agr}^{0}$ associated with [-realized] $\mathrm{T}^{0}$ can be extended to imperatives. From a formal point of view, it is tempting to say that the imperative agreement morphology is at least partly identical to that of infinitives. The reason for this is simplicity: if $\mathrm{T}^{0}$ morphemes with [-realized] temporal features are associated with anaphoric $\mathrm{AgrS}^{0}$ in infinitives, it is conceptually simpler to assume that some anaphoric $\mathrm{Agr}^{0}$ morpheme is also associated with the [-realized] $\mathrm{T}^{0}$ of imperatives: c-selectional properties between functional categories should be identical. At first sight, this cannot be the case: the imperative morphology is certainly distinct from the infinitival morphology. The imperative agreement morphology lacks a complete inflectional paradigm, but shows first and second person endings, unlike infinitives. The imperative tense morphology does not show [+past] markings, like the infinitival morphology, but unlike the infinitival morphology it can exhibit morphemes for the future and subjunctive endings. It is likely that the subjunctive agreement and temporal morphemes are present in the imperative $\mathrm{AgrS}^{\circ}$ and $\mathrm{T}^{\circ}$. Recall that we have assumed with Rivero (1988) that negation blocks movement of the verb to $\mathrm{C}^{0}$, triggering subjunctive morphology in most Romance languages. Since the verb does not move beyond $\mathrm{AgrS}^{0}, \mathrm{AgrS}^{0}$ and $\mathrm{T}^{0}$ must contain the relevant subjunctive and agreement morphemes. Only when the verb moves to $\mathrm{AgrC}^{0}$ can it receive the properly imperative morphology. For reasons of simplicity, it may then be assumed that the imperative $\mathrm{AgrS}^{0}$ and $\mathrm{T}^{0}$ are identical in every respect to 'normal' tensed morphology, since the imperative $\mathrm{AgrS}^{0}$ (2SG and $2 \mathrm{PL}, 1 \mathrm{PL}$ ) and $\mathrm{T}^{0}$ (subjunctive) morphemes are identical to the morphology of the verb in a tensed sentence. We would like to propose that it is the imperative $\mathrm{AgrC}^{0}$ which bears the [-realized] tense features in an imperative. This actually allows one to make sense of the fact that the imperative $\mathrm{T}^{0}$ can be subjunctive (Spanish, Portuguese, Italian, ...) or future (Latin): both the subjunctive mood and the future tense, but not past, are compatible with the feature [-realized] in the imperative $\mathrm{AgrC}^{0}$. In infinitives, however, $T^{0}$ itself bears the temporal [-realized] feature and can never exhibit subjunctive, past, or future morphology. We thus derive the fact that the imperative and infinitival tense morphology are syntactically and semantically similar, but not identical. 
What is the nature of the agreement features associated with the [-realized] $\mathrm{AgrC}^{0} ?^{6}$ We know that there are specific agreement morphemes for imperatives in some Romance languages (cf. supra). Moreover, since we have assumed that the imperative $\mathrm{AgrS}^{0}$ and $\mathrm{T}^{0}$ morphemes are identical to those of the tensed morphology, we have to derive the fact that imperatives are restricted to $2 \mathrm{sG}$, 2PL and 1PL. It is likely that the imperative $\mathrm{AgrC}^{0}$ is responsible for this restriction, but we have to find independent motivation for this conjecture. We would like to claim that this restriction is due to the basically anaphoric nature of the imperative $\mathrm{AgrC}^{0}$. Let us therefore return to the possible interpretations of clitic anaphors in Romance.

In recent work on the properties of reflexive se/si 'self' clitic anaphors in Romance (21), Burzio (1989) and Pica (1987, 1991) suggest that these reflexives are 'defective' morphemes in that they do not have $\Phi$-features at DS. Burzio (1989) and Pica $(1987,1991)$ suggest that the absence of $\Phi$-features is a morphological defining property of anaphors. Burzio (1989) moreover proposes that impersonal si 'self' in Italian is equally featureless, but lacks an antecedent since there is no governing category for it. Burzio (1989) proposes that impersonal $s i$ 'self' therefore receives a 'default' first person plural interpretation as in (22a). The impersonal si 'self' can however also refer to third person if context is supplied (22b).
a. Si è contenti in Italia. SELF is happy-PL in Italy
'One is happy in Italy.'
b. Tutti lo dicevano. Si è contenti in Italia. all it(CL) said. SELF is happy-PL in Italy 'Everyone said it. One is happy in Italy.'

Rooryck (1991) has argued that the same is true for anaphoric $\mathrm{AgrS}^{0}$ in certain infinitival clauses. In the cases where the infinitival clause is a complement of a matrix verb, the infinitival anaphoric $\mathrm{AgrS}^{0}$ is bound in its Binding domain, the matrix clause (cf. (20)).

When infinitives are not complements of the verb and hence lack thetamarking, there is no Binding domain for the infinitival $\mathrm{AgrS}^{0}$. In these cases, the infinitival clause will not only act as a barrier for extraction, but also for

6 We will not go into the question whether the [-realized] temporal/ modal features of the imperative $\mathrm{AgrC}^{0}$ and its agreement features are to be dissociated in two distinct projections or not. Since this problem is not relevant for the analysis at hand, we will simply assume that $\mathrm{AgrC}^{(1)}$ bears both the imperative temporal and agreement features. Beukema and Coopmans (1989) and Zanuttini (1991) have suggested that no nominative Case can be assigned to the imperative subject, since the imperative $\mathrm{T}^{0}$ is [-tensed]. We would like to reinterpret this suggestion and say that the presence of a [-realized] temporal value in $\mathrm{C}^{0}$ prevents Case assignment to the SpeclP position. 
Binding. This is the case for sentential subjects and infinitival adjuncts. The sentential subject in (23) is preferably interpreted as our/your making noise.

PRO making noise at midnight will frighten Sue.

The fact that PRO in these sentences is preferably interpreted as first or second person has been pointed out by Thompson (1973: 377) for adjectival arguments as in (24):

'Bill, tearing up my new paper dolls was mean,' cried Sue.

This referential property of PRO in sentential subjects has led Van Haaften (1982: 118) to claim that arbitrary PRO in these cases cannot be interpreted as third person. Bresnan (1982: 328) and Vanden Wyngaerd (1990: 216) have pointed out that the infinitival subject can be interpreted as referring to a third person if context is supplied:

a. Tom felt sheepish. Pinching those elephants was foolish. He shouldn't have done it.

b. Frankly, I'm worried about Mary. What has she gotten herself into? Don't get me wrong: I think it was fine to join the group. But getting herself photographed with those starving wolves was dangerous.

It is important to underscore that control of the infinitival subject in all these cases is not subject to locality restrictions as in (20). Despite examples such as (25), it is striking that the unexpressed subject PRO in infinitival and gerundial subjects is preferably interpreted as a discourse first or second person referent. Rooryck (1991) shows that the same is true in infinitival adjuncts when the subject of the infinitive does not correspond to the matrix subject. ${ }^{7}$ Clark (1985) has claimed on the basis of (26) that control in infinitival adjuncts is subject to locality. This claim is based on a rule of prescriptive grammar stipulating that the subject of the matrix clause should be a controller in adjunct infinitivals and gerunds. When making abstraction of this prescriptive reflex, sentences such as those in (27) can be construed which show that a nonlocal argument can control the unexpressed subject of a lower adjunct if it is second person, or properly introduced in the discourse: ${ }^{8}$

7 Rooryck (1991) shows that subject control in infinitival adjuncts does not come about via Binding of the infinitival $\mathrm{AgrS}^{0}$ in the matrix clause, but through a different mechanism. In infinitival idjuncts, the anaphoric $\mathrm{AgrS}^{0}$ has the option of coindexing with the subject through the temporal linking (Hornstein 1990) of the $T^{\circ}$ morphemes between the matrix and the adjunct clauses.

$\&$ It should be added that these sentences receive quite diverging acceptability judgments from various speakers. 
(26) Mary thought that Bill had died after seeing *herself/himself in the mirror.

(27) a. So you think now that Bill might have died right after shaving yourself on June 6 . Why would that be?

b. We have interviewed several people living in the neighborhood of the robbed bank. One person claimed the bank was attacked right after shaving himself at eight o'clock.

c. Bill will only come home after calling him repeatedly

d. Mr. Freckletweeter ${ }_{i}$ was a very disorderly person at times. $I_{j}$ see you $_{k}$ have realized now that without $\mathrm{PRO}_{\mathrm{i} / \mathrm{j} / \mathrm{k}}$ classifying them properly, his 's papers would have been irremediably lost for posterity.

Rooryck (1991) has pointed out that the interpretation of impersonal $s i$ 'self' in (22) is very close to the preferential interpretation of PRO in subject sentences and infinitival adjuncts: in both cases, the interpretation of the subject involves a discourse referent, but it can refer to third person given an appropriate context. The reflexive/impersonal si 'self' and the $\mathrm{AgrS}^{\circ}$ in subject sentences and infinitival adjuncts also share a syntactic context: in both cases, the anaphor does not have a governing category. We will assume here that gerunds and infinitives have the same type of anaphoric $\mathrm{AgrS}^{0}$. The similarity between the overt reflexive/impersonal si 'self', and the infinitival $\mathrm{AgrS}^{0}$ warrants an analysis of this infinitival $\mathrm{AgrS}^{0}$ along the same lines: the infinitival $\mathrm{AgrS}^{0}$ is an anaphor which can receive a 'default' pronominal interpretation if there is no governing category for it. Importantly, the infinitival $\mathrm{AgrS}^{0}$ is defined in terms of the Binding Theory.

The simplest hypothesis with respect to the nature of $\mathrm{AgrC}^{0}$ in imperatives then is to assume that it is also basically anaphoric in nature. Since imperatives cannot be embedded, there will never be a governing category for the imperative anaphoric $\mathrm{AgrC}^{0}$, and it will forcibly take a default first or second person pronominal interpretation. ${ }^{9,10}$ In this way, the imperative $\mathrm{AgrC}^{0}$ effectively

9 The fact that the imperative agreement morphology is restricted to first or second person is by no means a necessary property of the grammar. In fact, the value of the imperative for third person can very well be expressed in French by a root subjunctive clause with a spelled out complementizer:

(i) Qu'il parte s'il n'est pas content!

'That he leave, if he is not pleased!'

It should be stressed that these sentences are not to be analyzed as embedded clauses with a suppressed matrix clause, since it is not clear which verb this supposedly suppressed matrix clause should contain. They should be viewed as performative subjunctive clauses. Importantly, in the 
restricts the normal tensed morphology in the lower imperative $\mathrm{AgrS}^{0}$ and $\mathrm{T}^{0}$ to the attested 'defective' imperative morphology: 2SG and 2PL, and 1PL. This analysis can be reinforced by the observation that infinitives can be used as imperatives in Romance languages and in many languages not directly related to Romance. ${ }^{11}$

\section{Ne pas faire du bruit! \\ NEG not to make noise}

In the analysis developed here, this interpretation arises from the specific feature contents of the functional categories in the infinitive: the tense features of the infinitive are [-realized], and the infinitival $\mathrm{AgrS}^{0}$ receives a default pronominal 1 st or 2 nd person interpretation since no governing category is present. The semantic properties of the functional categories in nonembedded infinitives bring them very close to the semantic properties present in the functional categories of imperatives.

We may conclude that the claim that the imperative $\mathrm{AgrC}^{\circ}$ is anaphoric, however paradoxical at first sight, can be properly motivated. The default

analysis developed here, the anaphoric status of the imperative $\mathrm{AgrC}^{0}$ allows us to derive this otherwise unmotivated restriction of imperatives to first and second person.

The only element that remains unexplained under this analysis is why imperatives cannot refer to contextually introduced third person referents. This problem might be more general, however. In root sentences with impersonal si such as (22), the third person interpretation can only be obtained in context. In imperatives, the performative interpretation may play a role in excluding third person referents.

10 A reader for TLR points out that the referentiality of the anaphoric element in imperatives is more restricted than that of non-sententially bound infinitival Agr and se/si. In imperatives, it always takes a 'default' 1st or 2nd person interpretation, but infinitival Agr and se/si can take either a 'default' interpretation or a generic interpretation.

En aquél país se trabaja demasiado.

(Spanish)

in that country SELF works to much

'In that country, people work to much.'

(ii)

$\mathrm{PRO}_{\text {art }}$ to know her is $\mathrm{PRO}_{\text {arb }}$ to love her.

The possibility of a generic interpretation for infinitival Agr and se/si can be explained independently, however. Following Lebeaux (1984), we assume that the generic reading of (ii) arises from the presence of generic tense which acts as a universal operator unselectively binding PRO. This generic tense then provides PRO with its generic meaning. This analysis has been extended to unexpressed objects by Authier (1989), and can be equally applied to pro in the generic (i). The imperative anaphoric Agr will never be able to receive such a generic reading, since the imperative tense can never be generic.

11 In these cases, we have to assume that the infinitival $\mathrm{C}^{0}$ takes on an imperative value in addition to its [-realized] temporal feature. This additional imperative value of $\mathrm{C}^{0}$ explains why interrogative

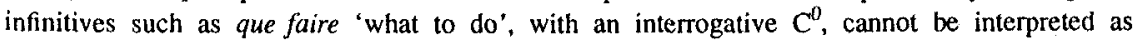
imperatives, since imperative and interrogative values are mutually exclusive. 
pronominal interpretation of the anaphoric $\mathrm{AgrC}^{0}$ can explain why imperatives are restricted to first and second person. Moreover, the minimal hypothesis with respect to the distribution of anaphoric and nonanaphoric $\mathrm{Agr}^{0}$ in the context of other functional categories suggests that anaphoric $\mathrm{Agr}^{0}$ should manifest itself in the context of [-realized] $T^{0}$. Functional categories have co-occurence restrictions expressible in terms of c-selection. Consequently, an infinitival [-realized] $\mathrm{T}^{0}$ should be accompanied by an infinitival $\mathrm{Agr}^{0}$ which we have argued to be anaphoric in nature. Finally, nonembedded infinitives can receive the interpretation of imperatives, a property which would go unexplained if their agreement morphemes had nothing in common. We are then allowed to adopt the strongest hypothesis, and claim that [-realized] $\mathrm{T}^{0}$ is always associated with an anaphoric $\mathrm{Agr}^{\circ}$ morpheme. This hypothesis is also the simplest, since it assumes a minimal set of possible interpretations for $\mathrm{Agr}^{0}$ morphemes in the grammar. $\mathrm{Agr}^{0}$ morphemes are only definable in terms of the Binding Theory in the context of [-realized] $\mathrm{T}^{0}$ (basically anaphoric with the possibility of a default pronominal interpretation). They are not definable in terms of Binding in normal tensed clauses where $\mathrm{Agr}^{0}$ is only subject to SpecHead agreement. A last question that needs to be answered in this context is why $\mathrm{Agr}^{0}$ morphemes would only be anaphoric in the case of [-realized] tense. We would like to suggest that this is due to the fact that [-realized] tense is in some sense an 'anaphoric' tense. Unlike embedded tensed clauses, embedded infinitives are dependent for the interpretation of their tense on the matrix verb (cf. Stowell 1982; Rooryck 1991). The properties of the $\mathrm{Agr}^{0}$ morphemes associated with $\mathrm{T}^{0}$ then simply mirror this 'anaphoric' nature.

\section{ANALYSIS: ANAPHORIC AGR ${ }^{0}\left(-S /-C^{0}\right)$ AS AN INTERVENING GOVERNOR FOR RM}

Coming back to (18) and reinterpreting it, we would like to argue that the definition of the imperative $\mathrm{AgrC}^{0}$ and the infinitival $\mathrm{AgrS}^{0}$ in terms of the Binding Theory, is responsible for clitics being left behind in the lower functional category. We have claimed that the infinitival $\mathrm{AgrS}^{0}$ and the imperative $\mathrm{AgrC}^{0}$ are anaphoric in nature, and can have a default pronominal interpretation. As such, they are identical in every respect to the Romance reflexive clitic se/si. Since these functional categories are defined in terms of the Binding Theory, they strongly resemble clitics. Clitics are either anaphors (se/si 'self') or pronouns (French le 'him/it', lui to-him/her' etc.).

Let us see what happens if the entire clitic-V-T-Agr complex would move to $\mathrm{AgrC}^{0}$. Within the resulting complex, the imperative anaphoric $\mathrm{AgrC}^{0}$ would dominate the clitics which are more deeply embedded in the morphological complex. 


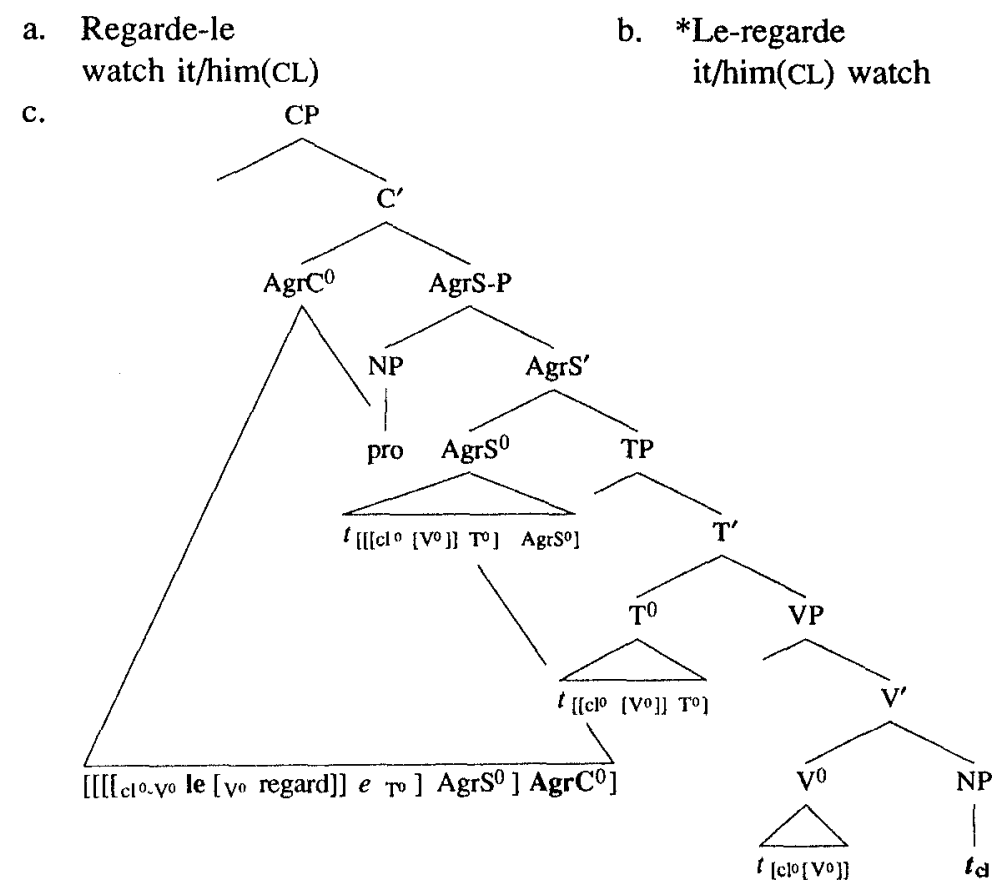

As such, $\mathrm{AgrC}^{0}$ would intervene between the clitic in $\mathrm{AgrC}^{0}$ and the trace of the clitic. $\mathrm{AgrC}^{0}$ interrupts the chain relating the clitic in the verbal complex to its trace. The relevant elements are highlighted in the structure $(29 \mathrm{c})$. We would like to claim that the fact that both clitics and the imperative $\mathrm{AgrC}^{0}$ and infinitival $\mathrm{AgrS}^{0}$ morphology are definable in terms of the Binding Theory enables these $\mathrm{Agr}^{0}$ morphemes to function as intervening governors for a relation between verb-adjoined clitics and their traces in a lower functional category. More concretely, in $(29 \mathrm{c})$, the anaphoric $\mathrm{AgrC}^{0}$ is a potential $\mathrm{X}^{0}$ governor for the trace of the clitic in the nonanaphoric $\mathrm{AgrS}^{0}$. Consequently, the trace of the clitic in $\mathrm{AgrS}^{0}$ would not be governed by the clitic in the anaphoric $\mathrm{AgrC}^{0}$, and the structure is ruled out by the Empty Category Principle, since the trace of the clitic is not governed. The only way for the verb to acquire the imperative morphology in $\mathrm{C}^{0}$ is to leave its clitics behind in $\mathrm{AgrS}^{0}$ so as to prevent an ECP violation from arising for its clitic subpart.

Exactly the same situation obtains with infinitives in Spanish and Italian (cf. (4a)), but this time it is the anaphoric nature of the infinitival $\mathrm{AgrS}^{0}$ which is involved. As noted before, the verb in these languages moves up all the way to $\mathrm{AgrS}^{0}$ in infinitival constructions (Belletti 1990). Since the infinitival $\mathrm{AgrS}^{0}$ is an anaphor, it acts as an intervening governor for Relativized Minimality, thus forcing the clitics to stay behind in the infinitival $\mathrm{T}^{0}$. We are in the presence of the same situation as with imperatives, with the difference that everything 
happens 'one notch down'. ${ }^{12}$ In French (4b), no such configuration involving Relativized Minimality can arise since the verb stays down in a projection lower than $\mathrm{AgrS}^{\circ}$. Consequently clitics are allowed to stay attached to the verb.

This move requires a slight modification of the definition of Relativized Minimality as it is proposed by Rizzi (1990), in the sense that the semantic contents of intervening governors is made more prominent than in Rizzi's original account. More specifically, we would like to add the following condition to the definition of Relativized Minimality in (5):

(iv) $\mathrm{Z}$ is semantically definable in the same terms as $\mathrm{X}$ and $\mathrm{Y}$. (Where 'semantically defined' refers to the way in which the feature content of $\mathrm{X}, \mathrm{Y}, \mathrm{Z}$ is interpreted by different modules of the grammar.)

This means that if a potential governor $Z$ intervenes between $X$ and $Y$ which is not semantically definable in the same terms as $\mathrm{X}$ and $\mathrm{Y}$, it will not block government of $\mathrm{Y}$ by $\mathrm{X}$. This modification of Relativized Minimality does not change anything for the core cases to be excluded by Relativized Minimality. ${ }^{13}$ In (6c), which is also excluded by Relativized Minimality applying to a case of $\mathrm{X}^{0}$ antecedent government, the intervening modal could clearly shares verbal AUX features with have and its trace, and hence counts as an intervening governor. In the case studied here, the semantic referential properties of Binding Theory are involved. The content of both anaphoric $\operatorname{Agr}\left(\mathrm{C}^{0} / \mathrm{S}^{0}\right)$ and clitics is semantically definable in terms of the Binding Theory, so the former can count as an intervening governor for the latter.

This approach of further semantically relativizing Relativized Minimality is in line with the modification proposed by Baker and Hale (1990). Baker and Hale (1990) argue that a distinction between functional and lexical categories should be built into the definition of Relativized Minimality: only lexical heads block antecedent-government by another lexical head, and only functional heads

12 This raises a problem for an analysis for clitic climbing along the lines of Kayne (1989), see $\$ 3$ for a possible solution.

13 This approach has a number of consequences for the analysis Rizzi (1990) offers of Inner Islands. For Rizzi (1990), negation can intervene between a wh-element in SpecCP and an intermediate trace in a lower SpecCP to block antecedent-government. Negation being an $A^{\prime}$ governor, Relativized Minimality rules out a sentence such as (i):

$$
\text { *[ } \left.\left[\mathrm{CP} \text { How didn't you think [ } \text { CP }_{\mathrm{i}} \text { Mary fixed the car } t_{\mathrm{i}}\right]\right]
$$

In the approach advocated here, negation would not be able to intervene as an $\mathrm{A}^{\prime}$ governor because it does not share any semantic features with the wh-chain it is supposed to block. On the basis a number of counterexamples to (i) in French, Rooryck (to appear) has shown that negative islands as in (i) should not be explained by Relativized Minimality. Rooryck (to appear) argues that the appropriate principles ruling out (i) have to do with operator - variable scope relations. 
block antecedent-government by another functional head. The modification of Relativized Minimality proposed here and Baker and Hale's (1990) proposal share the intuition that Relativized Minimality should take into account the content of intervening categories.

Crucially, the lower, nonimperative tensed $\mathrm{AgrS}^{0}$ does not have this blocking capacity for government in terms of Relativized Minimality. In the analysis developed here, this is because of the fact that tensed $\mathrm{AgrS}^{0}$ is different from both the imperative $\mathrm{AgrC}^{0}$ and the infinitival $\mathrm{AgrS}$ in that the 'normal' tensed morphology is not definable in terms of the Binding Theory. Tensed $\mathrm{AgrS}^{0}$ only acquires its nominal features through SpecHead Agreement. Since (29) does not apply to tensed $\mathrm{AgrS}^{0}$, tensed $\mathrm{AgrS}^{0}$ does not count as a potential $\mathrm{X}^{0}$ governor: that is, tensed $\mathrm{AgrS}^{0}$ is not 'visible' for a chain relating elements definable in terms of Binding their traces.

The analysis developed here claims that the notion 'potential $\alpha$-governor' within Relativized Minimality crucially involves the distinction between $\mathrm{Agr}^{0}$ morphemes definable in terms of the Binding Theory and $\mathrm{Agr}^{0}$ morphemes which are not so definable. This simply means that the contents of potential intervening governors does play a role in Relativized Minimality. The application of Relativized Minimality is restricted by the fact that the semantic content of an intervening head must be sufficiently similar to the content of elements of the chain it interrupts. A similar observation has been made for some exceptions to Rizzi's (1990) account of negative islands in terms of Relativized Minimality (Rooryck, to appear).

We still need independent evidence that $\mathrm{AgrC}^{0}$ is the relevant head involved here. In languages such as French where the imperative morphology is nondistinct from either the indicative (regarde 'watch-2SG' regardez 'watch2PL') or the subjunctive (sache 'know-2SG' sachez 'know-2PL') morphology, it could be claimed that it is in fact $\mathrm{AgrS}^{0}$ which is the relevant anaphor preventing clitics from moving up with the verb. This solution would then yield the same results in terms of Relativized Minimality without the assumption of $\mathrm{AgrC}^{0}$, since the whole structure would just be moved one notch down, with the clitics left behind in $\mathrm{T}^{0}$ instead of in $\mathrm{AgrS}^{0}$. This is in fact what happens in infinitives in Italian and Spanish. This hypothesis runs into several problems. First of all, it would be difficult to explain why negative imperatives, which presumably are in $\mathrm{AgrS}^{0}$ since they exhibit the morphological number distinctions, can and very often must have the clitics precede the imperative. If $\mathrm{AgrS}^{0}$ is the functional head involved in positive imperatives, we do not expect it to behave differently in negative imperatives. In our analysis, this is not a problem since the imperative $\mathrm{AgrS}^{0}$, being nonanaphoric, cannot function as a potential $X^{0}$ governor for the clitics. Hence we derive the fact that the unmarked position of clitics in negative Romance imperatives is in front of the verb. Recall that the verb has to stay in $\mathrm{AgrS}^{0}$, since the negation prevents it from raising to $\mathrm{C}^{0}$ (Rivero 1988). This is what happens in French, Spanish, Portuguese, and 
Standard Italian. In the marked Northern Italian dialects where clitics can follow the negated imperative cited in (7b) (Kayne 1991a), we may assume that $\mathrm{AgrS}^{0}$ has acquired the anaphoric properties of the imperative $\mathrm{AgrC}^{0}$, and hence behaves as $\mathrm{AgrC}^{0}$ with respect to Relativized Minimality. Consequently, in order to move to $\mathrm{AgrS}^{0}$, the verb has to leave behind its clitics in $\mathrm{T}^{0}$, exactly as in the case of infinitives (cf. fn.4).

Moreover, it seems that in languages such as French, the nonovert morphology of the positive imperative in $\mathrm{AgrC}^{0}$ licenses other types of morphophonological changes than those triggered by $\mathrm{AgrS}^{\circ}$. We would like to invoke here liaison phenomena which have been most extensively studied by Tranel (1981). Tranel (1981) analyzes verb liaison as the insertion of a phonological connector /z/ triggered by certain morphological contexts. Now imperatives followed by clitics do exhibit liaison phenomena with an clitic immediately following the verb, but it might be argued that this is an obligatory instance of a more general liaison rule which is optional in declarative contexts with words starting with a vowel as in (30b): ${ }^{14}$

$$
\begin{aligned}
& \text { Prends-/z/-en } \\
& \text { take of-it(CL) }
\end{aligned}
$$

b. Tu en prends $/ z /$ encore you of-it(CL) take more

There is however one case of liaison that is uncontrovertibly linked to the imperative morphology. Positive imperatives in French allow for a clitic-internal liaison which is not attested in any other context. More precisely, liaison can apply between a dative lui 'to him/her' clitic and an en 'of-it' clitic when they follow positive imperatives, but not in declaratives ( $31 \mathrm{~b}$ ), nor, more importantly, in negative imperatives (31c):
a. Donne lui-/z/-en give-2sG to-him/her(CL) of-it(CL)
b. *Tu lui-/z/-en donnes you to-him/her(CL) of-it(CL) give
c. ${ }^{*} \mathrm{Ne}$ lui-/z/-en donne pas
NEG to him/her(CL) of-it(CL) give-2SG NEG

14 However, see Tranel (1981) for arguments against such a view. The 'liaison' phenomenon in (15) is reported for at least one other Romance dialect of the 'langue d'oil' type, Walloon, by Remacle (1952: 250):

(i)

$$
\begin{aligned}
& \text { Dène-mu-z-è / Dè-m'z-è } \\
& \text { give-2sG to-me(CL) of-it(CL) }
\end{aligned}
$$

The second form is the abbreviated form of the first one. Thanks to Judy Bernstein for pointing out the Walloon data to me. 
In other words, positive imperatives are in different syntactic environments in (31a) and in $(31 \mathrm{~b}, \mathrm{c})$. For the sake of simplicity, then, it must be assumed that the clitic-internal type of liaison is triggered by the amalgamation of the verb with the nonovert imperative morphology in $\mathrm{AgrC}^{0}$, but not by the morphology in $\mathrm{AgrS}^{\circ}$ in declaratives and negative imperatives. In order to make this argument, it is sufficient to assume a phonological theory of liaison which accepts that liaison is sensitive to specific syntactic environments. Tranel's (1981) work on French liaison offers a framework in which such a relation is assumed for various types of liaison in French. For Tranel (1981), French liaison is triggered by various syntactic environments. Since the relevant liaison facts only occur in the syntactic environment of positive imperatives, we may safely assume that this environment is a different one from the one involved in tensed clauses and negated imperatives. In the analysis developed here, this is an additional argument that $\mathrm{AgrC}^{0}$, and not $\mathrm{AgrS}^{0}$, is the functional head to which the verb moves in Romance positive imperatives.

The resulting structure of positive imperatives followed by clitics as in (32a) is then as in (32b):

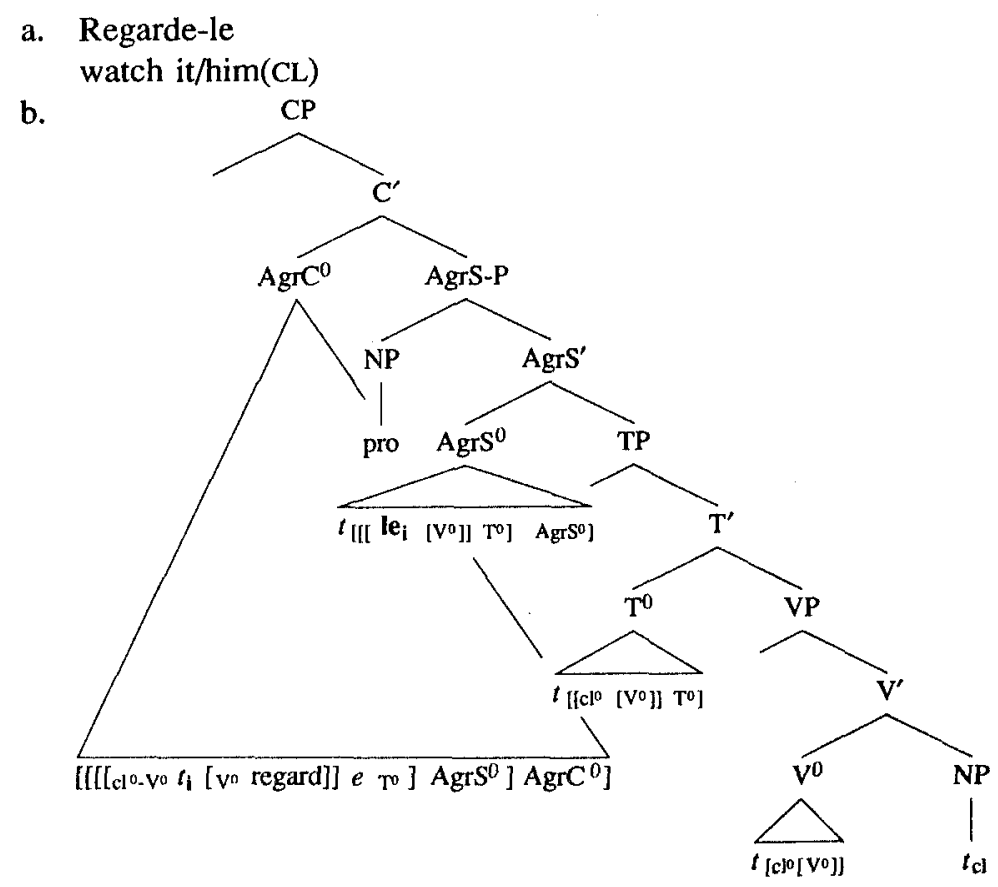

In this structure, the clitic trace in the verb complex in $\mathrm{AgrC}^{0}$ is properly governed by the verb. A first problem with this representation concems the status of the element subject to movement in (32). In the representation (32), 
movement of the verb cluster does not respect the constituent condition on movement, since a part of the verb cluster is left behind. However, this problem is entirely a result of the simplification we have introduced in our representation. Recall that for reasons of clarity we have assumed in fn. 4 a simplified bracketed representation for the complex head clusters. This representation did not represent the difference in connectivity between clitics which are moved by adjunction and $X^{0}$ morphemes which are moved by substitution (Roberts 1991). Under this analysis, it can be assumed that the part of the verb cluster moved in (32) does comply with constituenthood: in this case, movement only applies to the $\mathrm{V}^{0}-\mathrm{T}^{0}-\mathrm{AgrS} \mathrm{S}^{0}$ part of the verb cluster which has arisen through substitution, excluding the adjoined clitic. The analysis presented here then actually provides support for Roberts' (1991) analysis of the difference between incorporation of clitics and incorporation into functional categories.

At first sight, this structure also seems to violate Baker's (1988: 73) ban on traces within an $\mathrm{X}^{0}$ element, a constraint which he considers a morphological part of the Head Movement Constraint. Baker (1988) states this ban as follows:

$$
*\left[\begin{array}{lllll}
\mathrm{x}_{0} & \ldots & t_{\mathrm{i}} & \ldots
\end{array}\right]
$$$$
\text { (= Baker 1988: 73, ex. (76)) }
$$

The structure in (32b) clearly does not comply with this constraint. However, the constraint (33) was primarily designed by Baker (1988) to prevent a $Z^{0}$ incorporated to $\mathrm{X}^{0}$ to successive cyclically move to a higher $\mathrm{Y}^{0}$ as in (34):

$$
\left[\mathrm{Y}^{\circ} \mathrm{Z}^{0}\right] \ldots\left[\mathrm{X}^{\circ} t_{\mathrm{Z}^{\circ}}^{\prime}\right] \ldots t_{\mathrm{Z}^{\circ}}
$$

This configuration clearly does not obtain in (32b). Consequently, we feel justified in weakening Baker's (1988) principle by stating that the configuration (33) is allowed iff all the elements of the chain of the $\mathrm{Z}^{0}$ incorporating into the governing $\mathrm{X}^{0}$ are dominated by this $\mathrm{X}^{0}$. This is clearly the case in (32b), where the $\mathrm{V}^{0}$ in $\mathrm{AgrC}^{0}$ clearly dominates both the clitic and all its traces. This interpretation of Baker (1988: 73) still rules out the relevant structure (34), and is compatible with the exclusion of (34) via the Minimality Condition (Baker 1988: 451, fn.9): In this footnote, Baker (1988) attributes to Chomsky (p.c.) the idea that (34) may be ruled out by the ECP under an extension of the Minimality Condition, since XP would be a Barrier between $t_{Z^{\circ}}$ and its antecedent in $\mathrm{Y}^{0}$.

Another theoretical problem with the analysis of the enclitic ordering of imperatives in terms of Relativized Minimality has to do with the original definition of Relativized Minimality itself. Rizzi (1990: 7) characterizes this principle in hierarchical terms stipulating that an $\alpha$-governor $\mathrm{Z}$ intervening between $X$ and $Y$ must $c$-command $Y$ and not c-command $X$. In the case of enclitic imperatives, the intervening $\mathrm{AgrC}^{0}$ would clearly c-command both the clitic in the amalgamated verbal complex in $\mathrm{AgrC}^{0}$ and its trace in $\mathrm{AgrS}^{0}$ (cf. 29c). It could then be objected that Relativized Minimality cannot apply to this 
structure, since the hierarchical clause of its definition is not fulfilled. However, we would like to argue that the hierarchical relations between the elements amalgamated in an $X^{0}$ by adjunction are of a different nature from those expressed in a full-fledged configuration. For one thing, in order for a clitic to c-command its traces out of an $\mathrm{X}^{0}$ complex, it must be accepted in any case that they are somehow on the same hierarchical level as the functional $\mathrm{X}^{0}$ elements they are adjoined to together with the verb. Even if $\mathrm{AgrC}^{0} \mathrm{c}$-commands and governs the clitic in $(29 \mathrm{c})$, this c-command relation does not have the hierarchical property that was essential for Rizzi (1990) in determining intervention of a potential $\alpha$-governor hierarchically in terms of c-command. We would like to say that c-command in the strong hierarchical sense does not apply between $\mathrm{AgrC}^{\circ}$ and the clitic in (29c), since for all other purposes they are supposed to $b c$ on the same hierarchical level. Since the $\mathrm{X}^{0}$-complex in $\mathrm{AgrC}^{0}$ does c-command its complex trace and hence the trace of the clitic, Relativized Minimality does apply to (29c).

\section{SOME FURTHER PROBLEMS AND CONSEQUENCES}

The descriptive generalization that clitics follow imperatives does not extend to cases where the subjunctive is used as an imperative: in these cases, the clitics can precede the verb, as in Italian:

Gli scriva quella lettera che siamo in ritardo!

'To-him(CL) write-3SG:SUBJ that letter since we are late!'

Proclitic ordering with the imperative proper can occur in Albanian, given proper intonation (Aleksander Murzaku, p.c.):

Ua shkruaj ate leter se jemi vone!

'To-them(CL) write-2SG:IMP that letter since we are late!'

However, the forms used for the imperative in Albanian are identical to the first person singular and second person plural forms of the subjunctive for these verbs. It seems that the generalization only applies to those cases where the imperative morphology is independent of the subjunctive. In terms of the analysis we have developed, this means that in (36) the verb does not move up to $C^{0}$ whereas in (3a) with enclitic ordering, the verb does move up to $C^{0}$. These cases are then parallel to the cases of those languages where the subjunctive is used in negative imperatives: in both cases. the imperative value in $\mathrm{C}^{0}$ functions as an operator triggering the subjunctive morphology in $\mathrm{T}^{0}$. In the case of Albanian, the subjunctive in positive imperatives may move up to the nonovert imperative morphology in $\mathrm{AgrC}^{0}$ which will function as a potential $\mathrm{X}^{0}$ governor. 
Another apparent exception to the enclitic ordering in positive imperatives seems to be Brazilian Portuguese (Leslie Gabriele, p.c.):

$$
\begin{array}{lll}
\text { Dame! } & / \mathrm{Me} & \text { da! } \\
\text { give-2SG } \mathrm{me}(\mathrm{CL}) & / \mathrm{me}(\mathrm{CL}) & \text { give-2SG }
\end{array}
$$

The imperative with clitics preceding the verb has the present indicative morphology and is considered to be more polite. It also often requires the subjunctive morphology. This makes us suspect that these cases involve subjunctive or indicative root sentences which receive the illocutionary force of an imperative, much in the same way of English You be quiet!, where it can be assumed that an archaic subjunctive morphology functions as an imperative, perhaps as abbreviations of sentences such as I demand that you be quiet. A similar pattern also occurs in French, where the future indicative Vous nous laisserez tranquille 'You will leave us alone' receives the illocutionary force of a polite imperative. Since the languages involved in (35-37) are pro- drop, the subject can be left unexpressed. We will disregard these cases here, assuming an explanation along the lines suggested.

Pernot (1934: 189) mentions the existence of two dialect zones in Modern Greek with respect to the placement of personal pronouns, one type of dialects which have preposed pronouns in most forms except imperatives (cf. (3) and participles, and another type of dialect in which 'weak pronouns' are postposed in all verbal forms except the imperative (Brian Joseph, p.c.). Tsakonian is of the latter type: ${ }^{15}$

$$
\begin{array}{ll}
\text { a. } & \text { Eipe mou } \\
\text { tell-2SG } & \mathrm{me}(\mathrm{CL})
\end{array}
$$

$\begin{array}{ll}\text { b. } & \text { Mou pe } \\ \operatorname{me}(\mathrm{CL}) & \text { tell-2sG }\end{array}$

The distribution of these facts in Tsakonian suggests however that if the 'weak pronouns' in (38) are clitics, they are not clitics of the $\mathrm{X}^{0}$ type. It may be that these elements are in fact $X^{\max }$ pronouns which undergo cliticization at PF, along the lines suggested by Kayne (1983) for French subject clitics and English it (*He gave Mary it vs. It was given to Mary). Preposing of clitics in the case of the imperative might be due to movement the internal argument XP clitic to [Spec, CP] in order to allow PF cliticization in the domain of $\mathrm{C}^{0}$. This movement triggered by the imperative in $\mathrm{C}^{0}$ then resembles $\mathrm{V} 2$ phenomena.

We have already mentioned that clitic climbing is a problem for the approach to enclitic ordering advocated here. If the infinitival anaphoric $\mathrm{AgrS}^{0}$ is to intervene between the clitic and its trace in the case of enclitic ordering, the

15 Brian Joseph furthermore informs me that present-day Tsakonian exhibits the same clitic placement as Modern Greek, probably under the influence of the standard language. 
same situation should obtain in (39), where the clitic must have moved over the infinitival $\mathrm{AgrS}^{0}$ in order to end up in the matrix clause:

$$
\begin{aligned}
& \text { Lo voglio/ so fare. } \\
& \text { it(CL) I want to/ can do } \\
& \text { 'I want to/can do it.' }
\end{aligned}
$$

One way out of this problem would be to assume with Rochette (1988) that the set of verbs involving clitic climbing select a VP instead of a CP: in that case, there will be no embedded (and controlled) $\mathrm{AgrS}^{0}$ that might function as a potential $\mathrm{X}^{0}$ governor for the trace of the climbed clitics in the embedded VP, allowing clitics to move freely to the matrix $\mathrm{V}^{0} .{ }^{16}$ This analysis does not explain cases such as (40) with a wh-element in the embedded clause (Rizzi 1982; Kayne 1989):

?Non ti saprei che dire.
NEG to-you (I) would-know what to say

(Kayne 1989, ex. (16))

However, it seems that these cases are very restricted: my informants rule out the following: ${ }^{17}$
*Non ti
saprei
come dire
che la macchina era rotta.
NEG to-you
(I) would know how to tell that the car
was broken

Nevertheless, we would like to show that clitic climbing constructions as in (40) are not a problem for the analysis presented here. In order to make this argument, we would like to adapt Bouchard and Hirschbühler's (1986) analysis of French que 'what' to Italian. Bouchard and Hirschbühler (1986) show that French que 'what' is a clitic on the verb which forces movement to $\mathrm{C}^{0}$ of the clitic verb complex. It seems that the same is true for the clitic allomorph of Italian che 'what', to the extent that che cannot be separated from the verb by the subject in root clauses.

16 Alternatively, it might simply be that Kayne's analysis can be reconciled with an analysis invoking reanalysis for 'clitic climbing' verbs, following Rizzi (1982). See Rosen (1990) for a recent analysis along these lines.

17 Rizzi (1982: 36) quotes examples involving left dislocation contexts:

(i) 'Mario, non lo saprei a chi affidare, durante le vacanze.

Mario, I him wouldn't know to whom to entrust _ during the holidays

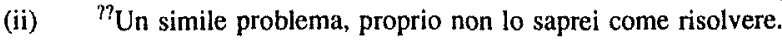

such a problem, I really wouldn't know how to solve

In view of (41), however, it is clear that the left dislocation contect is what saves these sentences. It seems that an analysis along the lines of Cinque (1991) is indicated for these cases. 

a. $L_{\mathrm{CP}}$ Que fait $\left[_{\mathrm{IP}}\right.$ il $\left.]\right]$ ?
what does he
b. *Il fait que
c. Che fa Gianni?/ * Che Gianni fa?

In embedded infinitives, the clitic character of che 'what' cannot be verified by the inversion of the subject, of course. However, elements such as negation cannot intervene between che 'what' and the verb. If cosa 'what', the non-clitic $\mathrm{XP}$ allomorph of che 'what' is in SpecCP, negation is possible.
a. *Non sapevo che non dirgli. 'I did not know what not to say to him.'
b. Non sapevo che dirgli. 'I didn't know what to say to him.'

(44) Non sapevo cosa non dirgli.

'I didn't know what not to say to him.'

Clitic wh-elements such as que/che in embedded sentences have to move to the embedded $\mathrm{C}^{0}$ in order to license their wh-property, in accordance with Rizzi's (1991) Wh-criterion. We would like to propose that in Italian movement of che to $\mathrm{C}^{0}$ takes place via movement of the che-infinitive complex to Agr-S ${ }^{0}$. From the Agr-S $S^{0}$ position, which is governed by the $[+w h] C^{0}$, the clitic che excorporates to $\mathrm{C}^{0}$ and yields (43b). We are now in a position to explain (43a): negation prevents the clitic che from excorporating into $\mathrm{C}^{0}$ and thus from verifying its $w h$-properties. In (44) the non-clitic wh-element cosa can move to SpecCP, unbothered by negation.

Let us come back now to the way in which clitic climbing takes place in (40). In fact, there is another option for che to satisfy its wh-properties which involves movement of the entire verb complex che ti dire to $\mathrm{C}^{0}$, rather than excorporation of che alone out of the infinitival Agr- $S^{0}$ position. In this case, the verbal complex moves with che to $\mathrm{C}^{0}$ in the way of tensed verbs as in (42). Notice that movement of the entire verb complex or excorporation of che alone carry the same cost. From the position of the embedded verb complex in $\mathrm{C}^{0}$, the clitic $t i$ 'you' then excorporates to the matrix verb, a legitimate trigger for excorporation of clitics. This yields the following structure for (40):

$$
\text { Non } t_{\mathrm{j}} \text { saprei }\left[_{\mathrm{CP}} \text { che } t_{\mathrm{j}} \text { dire } L_{\mathrm{IP}}\left[\mathrm{VP}, t_{\mathrm{dine}} t_{\mathrm{j}} 1\right]\right]
$$

Only when the $\mathrm{V}^{0}-\mathrm{T}^{0}-\mathrm{AgrS}^{0}$ complex has moved $\mathrm{C}^{0}$ at $\mathrm{S}$-structure can the clitic escape to the matrix clause. Moreover, clitic movement is obligatory in this case. The clitic che will not move any further because of the fact that it has to satisfy 
its $w$-properties in the lower $\mathrm{C}^{0}$. The sentence (41) is excluded because of the fact that nothing forces movement of the verb complex to $\mathrm{C}^{0}$, come 'how' being in the SpecCP. As a consequence, the clitic-verb complex is not high enough for the clitic to excorporate into the matrix verb. ${ }^{18}$

What about Relativized Minimality and the quality of $\mathrm{AgrS}^{0}$ as an intervening governor for the relation between the climbed $t i$ 'you' and its trace in the VP? Since the anaphoric $\mathrm{AgrS}^{0}$ has moved to $\mathrm{C}^{0}$ with the $\mathrm{V}^{0}-\mathrm{T}^{0}$ complex, it does not fulfill any longer clause (i) of the definition of Relativized Minimality in (6): $\mathrm{Z}$, in casu $\mathrm{AgrS}^{0}$, is no longer in a base-generated position and therefore cannot count as an intervening governor for the relation betwen the climbed clitic $t i$ 'you' and its trace in the lower VP.

It is not clear to us why this mechanism is limited to Italian. In any case, clitic climbing involves an exceptional mechanism in that the crossing of a clitic from one sentential domain into another is limited to a subset of verbs. Even though we have been mainly concerned with the more basic question of clitic ordering within a single sentential domain, it is clear that sentences such as $(40-45)$ do not constitute a problem for the approach to enclitic ordering in Romance advocated here.

A last interesting consequence of this approach is that Kayne's (1991a) analysis of the differences between French, Italian, and Sardinian with respect to both clitic and adverb ordering can be preserved without using $\mathrm{V}^{0}$ adjunction to $I^{\prime}$. Kayne (1991a) has formulated the important generalization that Romance languages with infinitive + clitic ordering allow si 'if' in $\mathrm{C}^{0}$, whereas languages with clitic + infinitive ordering do not allow this construction:

a. *Marie ne sait pas si aller au cinéma. (= Kayne 1991a. ex. (49)) 'Marie doesn't know whether (if) to go to the movies.'

b. Gianni non sa se andare al cinema. (= Kayne 1991a, ex. (65)) 'Gianni does not know whether (if) to go to the movies.'

Kayne (1991a) explain this generalization in terms of adjunction of the verb to the $I^{\prime}$ projection, a rather exceptional kind of head movement. The analysis pursued here commits us to an alternative explanation of this generalization. We would like to suggest that in order to be licensed, the si 'if' element expressing Eventuality in $\mathrm{C}^{0}$ must govern an element that corresponds to this notion. This

18 Notice that the same mechanism could be extended to the usual cases of clitic climbing in (39): if the infinitival complement in (39) is a CP rather than a VP, it could be assumed that the verbal complex moves all the way to the embedded $\mathrm{C}^{0}$, allowing the clitic to excorporate into the matrix clause. The trigger for movement to $C^{0}$ could then be related to selectional restrictions on $C^{0}$ by the set of verbs which allow for clitic climbing in Italian: epistemic, aspectual, modal and movement verbs (see Rooryck 1992). Pearce (1990) notes that in Old French a much wider class of verbs allowed for clitic climbing. 
is merely a selectional requirement imposed by si 'if' under government. AgrP clearly cannot comply with the selectional properties of si 'if', since it is a purely nominal element. Only in languages moving the V-INF-T complex up to $\mathrm{AgrS}^{0}$ will this requirement be met, since only $\mathrm{V}$ and temporal/modal morphemes can satisfy the selectional 'Eventuality' requirement of si 'if'. ${ }^{19}$ The notion 'Eventuality' with respect to infinitives corresponds to the modal interpretation of the temporal feature [-realized] (cf. supra). We would simply like to observe that the 'Eventuality' selectional requirement of $s i$ 'if' can be satisfied by the temporally 'hypothetical/unrealized/in posse' properties of the infinitival morphology.

Notice that we are not saying that the infinitive moves to $\operatorname{Agr} S^{0}$ in order to satisfy the selectional requirement, because that would not explain why in French-Sardinian the infinitive doesn't move to $\mathrm{AgrS}^{0}$. In our analysis, whatever conditions are responsible for moving up the infinitive as far as $\mathrm{AgrS}^{0}$ in Italian-Spanish also allow si 'if' to satisfy its selectional properties.

\section{CONCLUSION}

Our analysis of enclitic ordering in Romance imperatives and infinitives in terms of Relativized Minimality strongly suggests that amalgamated categories are not an unordered bunch of features, but that the morpheme boundaries within the amalgamated complex are preserved. ${ }^{20}$ It shows that a purely syntactic principle such as the ECP applies to morphologically amalgamated categories (Baker 1988). Morpheme boundaries are nevertheless different from purely syntactic boundaries in that amalgamated morphemes and their features are visible within the whole complex no matter how many morpheme boundaries intervene.

The analysis of clitic ordering in Romance imperatives advocated here offers strong evidence for Kayne's analysis of $\mathrm{X}^{0}$ amalgamation as involving a general left adjunction process. It is also worthwhile to note that the enclitic ordering in Romance imperatives can be considered a case of reverse excorporation (Roberts 1991): instead of the clitic 'passing through' the V-T-Agr complex, here the verb excorporates into $C^{0}$ because of general principles of the grammar which determine that it cannot take its clitics with it. The analysis presupposes that the grammar makes a distinction between $\mathrm{Agr}^{\circ}$ morphemes that are defined in terms of the Binding Theory and $\mathrm{Agr}^{\circ}$ morphemes that are not so defined.

19 With respect to the Projection Principle (selectional properties must be satisfied at each level of representation), this analysis of course entails that it is sufficient for nonthematic selectional properties to be satisfied at S-structure.

20 For another exploitation of the idea that features in amalgamated V-T-Agr complexes are distinctly visible in causatives, see d'Hulst and Rooryck (1989). 
The analysis strongly suggests that Relativized Minimality applies to the morphosyntactic complexes of clitics, verbs and affixes, and has to integrate a more precise definition of potential $\mathrm{X}^{0}$ governors which takes into account their semantic content.

\section{REFERENCES}

Albertini, J. (1972). Précis de grammaire corse. Corté: Editions du CERC.

Authier, J.-M. (1989). Arbitrary null objects and unselective binding. In Osvaldo Jaeggli and Ken Safir (eds.), The null subject parameter. Dordrecht: Kluwer, p. 45-67.

Baker, Mark (1988). Incorporation: a theory of grammatical function changing. Chicago: University of Chicago Press.

Baker, Mark and Ken Hale (1990). Relativized Minimality and pronoun incorporation. In Linguistic Inquiry 21: 289-297.

Bec, P. (1967). La langue occitane. Paris: Presses Universitaires de France.

Belletti, Adriana (1990). Generalized verb-movement. Ms., Université de Genève - Scuola Normale Superiore Pisa.

Beukema, Frits and Peter Coopmans (1989). A government-binding perspective on the imperative in English. In Journal of Linguistics 25: 417-436.

Bresnan, Joan (1972). Theory of complementation in English syntax. Doctoral dissertation, MIT.

Bresnan, Joan (1982). Control and complementation. In Linguistic Inquiry 13: 343-434.

Bouchard, Denis and Paul Hirschbühler (1986). French quoi and its clitic allomorph que. In Carol Neidle and Rafael Nuñez Cedeño (eds.), Studies in Romance languages. Foris: Dordrecht, p. 39-60.

Burzio, Luigi (to appear). On the morphology of reflexives and impersonals. In Proceedings of the 19th Annual Linguistic Symposium on Romance Languages (Columbus, Ohio, April 21-23, 1989).

Chomsky, Noam (1989). Some notes on economy of derivation and representation. In: Itziar Laka and Anoop Mahajan (eds.), Functional heads and clause structure. MIT Working papers in linguistics 10, p. $43-74$

Cinque, Guglielmo (1991) Types of $A^{\prime}$-dependencies. MT Press, Cambridge, Massachusetts.

Clark, R. (1985). Boundaries and the treatment of control. Doct. diss. UCLA.

d'Hulst, Y. and J. Rooryck (1989). An ECM analysis of French perception and transitive movement verbs. Paper presented at the LSA Winter meeting, 1989, Washington, D.C. Ms., Leiden University/Indiana University.

Guillaume, G. (1929). Temps et verbe. Paris: Masson.

Haaften, Ton van (1982). Interpretaties van begrepen subjecten. In Glot 5: 107-122.

Haiman, J. (1988). Rhaeto-Romance. In M. Harris and N. Vincent (eds.), The Romance languages. New York: Oxford University Press, 351-390.

Hornstein, Norbert (1990). As time goes by: Tense and universal grammar. Cambridge (Mass.): MIT Press.

Jaeggli, Osvaldo (1986). Three issues in the theory of clitics: Case, doubled NPs and extraction. In Hagit Borer (ed.), The syntax of pronominal clitics. New York: Academic Press, 15-42.

Jones, M. (1988). Sardinian. In Martin Harris and Nigel Vincent (eds.), The Romance languages. New York: Oxford University Press, 314-350.

Joseph, B. (1983). The synchrony and diachrony of the Balkan infinitive, a study in areal, general, and historical linguistics. Cambridge: Cambridge University Press.

Kayne, Richard (1983). Chains, categories external to S, and French complex inversion. In Natural Language \& Linguistic Theory 1: 107-139.

Kayne, Richard (1989). Null subjects and clitic climbing. In O. Jaeggli and K. Safir (eds.), The null subject parameter. Dordrecht: Kluwer, p. 239-261.

Kayne, Richard (1991a). Romance clitics, verb movement, and PRO. In Linguistic Inquiry 22: 647-686. 
Kayne, Richard (1991b). Italian negative infinitival imperatives and clitic climbing. Ms. CUNY Graduate Center.

Lebeaux, David (1984). Anaphoric binding and the definition of PRO. In C. Jones and P. Sells (eds.), Proceedings of NELS 14, Amherst: GLSA, p. 253-274.

Manzini, Maria Rita (1983). On control and control theory. In Linguistic Inquiry 14: 421-467.

Newmark, L., P. Hubbard and P. Prifti (1982). Standard Albanian. Stanford: Stanford University Press. Pearce, E. (1990). Parameters in Old French syntax: infinitival complements. Dordrecht: Kluwer.

Pernot, H. (1934). Introduction a l' étude du dialecte tsakonien. Paris: Les Belles Lettres.

Pica, Pierre (1987). On the nature of the reflexivization cycle. In J. McDonough and B. Plunkett (eds.), Proceedings of NELS 17, Amherst: GLSA, p. 483-500.

Pica, Pierre (1991). On the relationship between binding and antecedent-government: the case of long-distance reflexives. In Jan Koster and Eric Reuland (eds.), Long-distance anaphora. Cambridge: Cambridge University Press, p. 72-98.

Pizzini, Q. (1981). The placement of clitic pronouns in Portuguese. In Linguistic Analysis 5: 293-312.

Pollock, Jean-Y. (1989). Verb movement, Universal Grammar, and the structure of IP. In Linguistic Inquiry 20: $365-424$.

Remacle, L. (1952). Syntaxe du parler wallon de la Gleize. Tome 1. Paris: Les Belles Lettres.

Rézean, P. (1976). Un patois de Vendée, le parler rural de Vouvant. Paris: Klincksieck.

Rivero, M-L. (1988). The structure of IP and V-movement in the languages of the Balkans. Ms., University of Ottawa.

Rizzi, Luigi (1982). Issues in Italian syntax. Dordrecht: Foris.

Rizzi, Luigi (1990). Relativized minimality. Cambridge (Mass.): MIT Press.

Roberts, Ian (1991). Excorporation and minimality. In Linguistic Inquiry 22: 209-218.

Rochette, Anne (1988). Semantic and syntactic aspects of Romance sentential complementation. Doctoral dissertation, MIT.

Rooryck, Johan (1991). Out of control. Deriving the reference of unexpressed infinitival subjects. Ms., Indiana University.

Rooryck, Johan (1992). On some hurdles for clitic climbing (and how to overcome them). Ms., Indiana University.

Rooryck, Johan (to appear). Negative and factive islands revisited. In Journal of Linguistics 28: 1/2.

Rohlfs, G. (1977). Le gascon: études de philologie pyrénéenne. Tübingen: Niemeyer - Pau: Marrimpouey Jeune.

Rosen, S. (1990). Restructuring verbs are light verbs. In Aaron Halpern (ed.), Proceedings of the Ninth West Coast Conference on Formal Linguistics, Stanford: CLSI, p. 477-492.

Rouveret, Alain (1989). Cliticisation et temps en portugais européen. In Revue des langues romanes 93: $337-372$.

Sauzet, P. (1986). Les clitiques occitans: analyse métrique de leur variation dialectale. Morphosyntaxe des langues romanes. In Actes du XVIT congres international de linguistique et de philologie romanes. Vol 4, Aix-en Provence: Université de Provence, p. 153-180.

Stowell, Tim (1982). The tense of infinitives. In Linguistic Inquiry 13: 561-570.

Thompson, S. (1973). On subjectless gerunds in English. In Foundations of language 9: 374-383.

Tranel, Bernard (1981). Concreteness in generative phonology. Berkeley: University of Califomia Press.

Vanden Wyngaerd, Guido (1990). PRO-legomena. An investigation into the distribution and the referential properties of the empty category PRO. Doctoral dissertation, Universitaire Instelling Antwerpen.

Zanuttini, Raffaella (1991). Syntactic properties of sentential negation: a comparative study of Romance languages. Doctoral dissertation, University of Pennsylvania. IRCS Report $\mathrm{n}^{\mathrm{Q}}$ 91-26.

Indiana University

Ballantine Hall 642

Bloomington. Indiana 47405

U.S.A. 